\title{
Rancang Bangun Pembangkit Listrik Hybrid Tenaga Surya dan Bayu Untuk Simulasi Pompa Aerator Kolam 25 W
}

\author{
Uray Muhammad Devrifqi'; Muhammad Imbarothur Mowaviq ${ }^{2}$ \\ 1,2 Institut Teknologi PLN \\ ${ }^{1}$ devrifqi99@gmail.com
}

\begin{abstract}
Electrical energy is one of the energies that has become a primary demand for society. In the production of electrical energy, a power plant is needed which in its production does not give a negative impact on the environment. Therefore, developing eco-friendly technology power plants which are often referred to as EBT (New Renewable Energy) is being intensified, the simulation of combining PLTS and PLTB into a single hybrid system with offgrid mode can be an alternative solution to the above problems. The system is designed with the flow of solar and wind power plants being combined into one through a $700 \mathrm{~W}$ hybrid controller, then from the controller, it will be connected to the battery with a voltage of $12 \mathrm{~V}$, and from the battery, it will continue flow to the pool aerator pump load of $25 \mathrm{~W}$ with voltage conversion from $12 \mathrm{~V}$ to $220 \mathrm{~V}$. using an inverter. From the results of monitoring data loggers, the average energy per day that can be produced by PLTS is in the range of 316.84 Wh. While the average energy per day that can be produced by PLTB is in the range of $67.77 \mathrm{Wh}$. Then on the results of loT monitoring, it is found that the average energy that can be used by the load in a time range of 14.2 hours is $242.25 \mathrm{Wh}$. There is residual energy of 142.36 Wh which can be stored in the battery.
\end{abstract}

Keywords: PLTB, PLTS, Hybrid

\begin{abstract}
ABSTRAK
Energi Listrik adalah salah satu energi yang sudah menjadi kebutuhan primer bagi masyarakat. Dalam produksi energi listrik, dibutuhkan pembangkit tenaga listrik yang dalam produksinya tidak merugikan lingkungan yang ada di sekitar. Oleh karena itu teknologi pengembangan pembangkit listrik ramah lingkungan yang sering disebut dengan sebutan EBT (Energi Baru Terbarukan) sedang digencarkan, simulasi penggabungan antara PLTS dan PLTB menjadi satu kesatuan sistem hibrida dengan mode off-grid dapat menjadi salah satu solusi alternatif dari permasalahan diatas. Sistem dirancang dengan alur dari pembangkit tenaga surya dan angin dijadikan menjadi satu melalui controller hybrid $700 \mathrm{~W}$, kemudian dari controller akan disalurkan menuju baterai dengan tegangan $12 \mathrm{~V}$ dan dari baterai akan diteruskan ke beban pompa aerator kolam $25 \mathrm{~W}$ dengan pengkonversian tegangan dari $12 \mathrm{~V}$ ke $220 \mathrm{~V}$ menggunkan bantuan inverter. Dari Hasil monitoring data logger, energi rata - rata per hari yang dapat dihasilkan oleh PLTS adalah kisaran sebesar 316,84 Wh. Sedangkan energi rata - rata per hari yang dapat dihasilkan oleh PLTB adalah kisaran sebesar 67,77 Wh. Lalu pada Hasil monitoring loT, didapatkan energi rata - rata yang dapat digunakan beban dalam kisaran waktu 14,2 jam adalah sebesar 242,25 Wh. Terdapat energi sisa sebesar 142,36 Wh yang dapat disimpan ke dalam baterai.
\end{abstract}

Kata Kunci: PLTB, PLTS, Hybrid 


\section{PENDAHULUAN}

Instalasi Pada era industri 4.0 yang merupakan era digital dimana sesuatu tidak dilakukan lagi dengan cara manual, tetapi dilakukan secara jarak jauh dan sistem - sistem yang dikontrol menggunakan jarak jauh ini membutuhkan sebuah energi yang dinamakan dengan energi listrik. Energi listrik sudah menjadi salah satu kebutuhan yang tergolong primer, sehingga menyebabkan adanya kenaikan kurva permintaan energi listrik untuk memenuhi kebutuhan para konsumen sehari - hari. Naiknya kurva permintaan pada bidang energi listrik ini harus diseimbangkan juga dengan efek yang ditimbulkan pada lingkungan sekitarnya. Seperti yang diketahui bahwa salah satu penyuplai pasokan tenaga listrik terbesar di Indonesia adalah Pembangkit Listrik Tenaga Uap (PLTU) yang memiliki bahan bakar berupa batu bara/fosil. Bahan bakar seperti ini bukanlah bahan bakar yang ramah akan lingkungan. Tidak hanya teknologi saja yang harus maju melainkan kesehatan dunia ini juga harus menjadi salah satu faktor terpenting yang harus dijaga semaksimal mungkin untuk kepentingan bersama.[1]

Energi Baru Terbarukan ini sangatlah berpotensi untuk mengatasi energi fosil yang semakin menipis dari tahun ke tahun, dimana salah satunya yang paling banyak beredar saat ini adalah Pembangkit Listrik Tenaga Surya (PLTS) dan Pembangkit Listrik Tenaga Bayu (PLTB), PLTS adalah pembangkit yang menghasilkan listrik dengan sumber yang sederhana dan gratis, yaitu matahari dimana energi cahaya yang dihasilkan oleh matahari ini akan dikonversikan ke dalam energi listrik dan seperti yang kita ketahui juga bahwa matahari adalah sumber daya yang menerangi dunia ini setiap hari demi hari. Begitu juga dengan PLTB yaitu pembangkit yang membutuhkan sumber daya berupa angin yang juga merupakan sumber daya alam yang setiap hari bersirkulasi di dunia baik di siang hari maupun di malam hari. Gerak putaran yang disebabkan oleh angin ini menjadi sumber energi gerak yang akan dikonversikan menjadi sebuah energi listrik. Oleh karena itu pada kesempatan kali ini, penulis ingin membuat simulasi sistem pembangkit hibrida antara Pembangkit Listrik Tenaga Surya (PLTS) dan Pembangkit Listrik Tenaga Bayu (PLTB), melihat terdapat potensi besar pada kedua pembangkit tersebut untuk memenuhi kebutuhan beban di daerah pesisir pantai, dimana pada lokasi pesisir pantai ini mempunyai kecepatan angin yang cukup kencang dan juga tentunya terdapat terik panas matahari yang cukup. [2]

Hibrida kedua pembangkit ini merupakan suatu kombinasi yang baik dimana dua pembangkit trsebut sama - sama bersifat intermiten. definisi dari pembangkit yang bersifat intermiten adalah pembangkit yang mempunyai sifat berselang - seling antara iya dan tidak dalam mensuplai daya listrik, mengingat sumbernya adalah angin yang tidak selalu konstan kecepatannya untuk PLTB dan cahaya yang hanya ada di siang hari untuk PLTS. Oleh karena itu diperlukannya sebuah baterai untuk menangkap daya yang disalurkan oleh kedua pembangkit intermiten ini dan kontroller yang digunakan adalah Wind Solar Hybrid Controller $700 \mathrm{~W}$ yang merupakan sebuah kontroller baru karena tidak memerlukan sistem kontrol secara terpisah untuk daya masukan dari panel surya dan turbin angin.Pembangkit Listrik Hibrida Tenaga Surya dan Bayu ini dirancang dengan kapasitas $700 \mathrm{~W}$ karena kedepannya akan di gunakan untuk memenuhi kebutuhan beban - beban lain yang cukup besar, oleh karena itu pada penelitian kali ini Beban yang digunakan adalah berupa beban simulasi penelitian yang hanya memerlukan daya sebesar $25 \mathrm{~W}$, yaitu pompa aerator kolam untuk melihat bagaimana keluaran dari sistem pembangkit hibrida ini ketika akan digunakan sebagai sumber off grid. [3] 


\section{METODE/PERANCANGAN PENELITIAN}

\subsection{Alat dan Bahan Penelitian}

Bahan yang digunakan dalam penelitian kali ini adalah sebagai berikut:

1. Panel surya Monocyrstalline 100wp (4 buah)

2. Turbin angin generator 3 fasa $12 \mathrm{~V} 300 \mathrm{~W}$

3. PWM Wind Solar Hybrid Charge Controller

4. Baterai Panasonic LC-P1265NA 12V 65 AH (2 buah)

5. Hanaya Inverter Modified Sine Wave $1500 \mathrm{~W}$

6. Atman Power Liquid Filter $25 \mathrm{~W}$

7. Arduino Uno R3 (3 buah)

8. NodeMCU ESP 8266 V3

9. Sensor Tegangan AC ZMPT101B (2 buah)

10. Sensor Tegangan DC Divider 0-25V

11. Sensor Arus ACS712 (2 buah)

12. RTC DS3132 dan DS 1302

13. Modul LCD dan Modul I2C

14. Anemometer

15. $\mathrm{BH} 1750$

Pengambilan data pada pembangkit listrik hybrid tenaga surya dan angin dilakukan dengan cara monitoring tegangan dan arus yang dihasilkan oleh PLTS dan PLTB berbasis Data Logger, kemudian monitoring juga tegangan dan arus yang disupply menuju beban berbasis loT. Lalu dilakukan juga monitoring kecepatan angin yang akan diukur dengan anemometer dan intesitas cahaya yang akan diukur dengan $\mathrm{BH} 1750$ untuk melihat nilai pengaruh antara tegangan, arus, kecepatan angin dan intensitas cahayanya. [4]

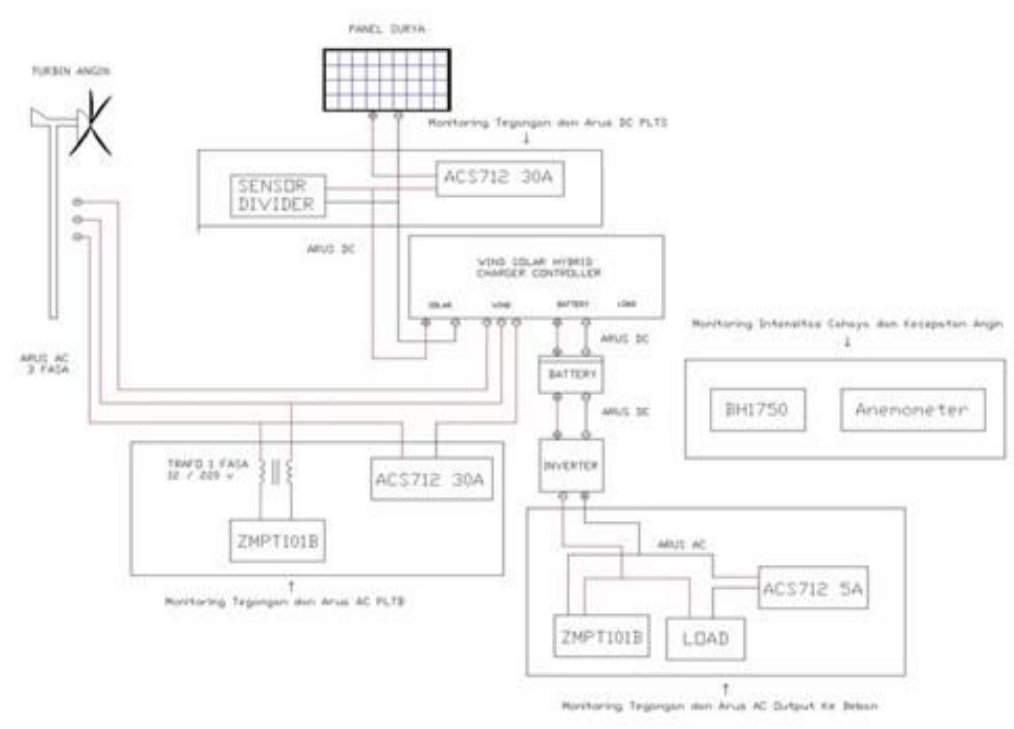

Gambar 1. Skema Perancangan Sistem Hybrid PLTS dan PLTB

Sistem dibuat dengan menyambungkan 3 fasa keluaran generator PLTB menuju PWM Wind Solar Hybrid Charge Controller, namun sebelumnya dilakukan pemasangan alat ukur untuk monitoring tegangan dan arus yang berbasis Data Logger dimana tegangan 
diukur menggunakan ZMPT101B yang dipasangkan secara paralel dimana dipasangkan pengukuran antara tegangan fasa $S$ dan fasa $T$. sedangkan untuk arus dilakukan pengukuran menggunakan ACS712 yang dipasang seri pada fasa T. Setelah PLTB, terdapat juga keluaran DC 4 panel surya yang diparalel kemudian dihubungkan menuju PWM Wind Solar Hybrid Charge Controller, sebelum masuk ke controller juga diberikan alat ukur untuk monitoring arus dan tegangan yang berbasis Data Logger dimana tegangan dipasang secara paralel menggunakan sensor tegangan DC divider $0-25 \mathrm{~V}$ dan arus dipasang secara seri menggunakan sensor ACS712. Kemudian setelah arus dan tegangan dari PLTS dan PLTB masuk ke controller maka akan dilakukan pengaturan agar tidak terjadi pengisian yang berlebih, masuk nya arus pendek yang dapat merusak komponen dari baterai atau beban. Setelah dari controller kemudian dilanjutkan menuju baterai untuk dilakukan penyimpanan energi, setelah dari baterai arus DC akan diubah menjadi arus AC menggunakan Inverter untuk dapat mensuplai daya pada beban simulasi yaitu pompa air sebesar 25 Watt. Sebelum menuju pompa, dipasangkan alat monitoring loT arus dan tegangan dimana arus diukur menggunakan ACS712 yang dipasang secara seri dan tegangan diukur mengunakan ZMPT101B yang dipasang secara paralel.

\subsection{Metode Penelitian}

1. Studi Literatur

Peneliti mempersiapkan penelitian dengan cara mengumpulkan sumber - sumber yang berkaitan dengan identifikasi masalah yang sama, kemudian peneliti mencatat dan mengolah kembali dari bahan penelitian sebelumnya:

1. Mempelajari karaketeristik dari panel surya

2. Mempelajari karakteristik dari turbin angin

3. Mempelajari tentang wind hybrid solar controller

4. Mempelajari karakteristik dari baterai

5. Mempelajari karakteristik dari inverter

6. Mempelajari karakteristik dari pompa aerator kolam

7. Mempelajari tentang sensor arus, tegangan, intensitas cahaya dan kecepatan angin

8. Mempelajari karakteristik mikrokontroler yang digunakan

9. Mempelajari tentang alat monitoring sensor yang dipakai

2. Membuat Rancang Bangun

Peneliti melakukan pembuatan rancangan dengan cara membuat skema dan rangkaian sistem Pembangkit Listrik Hibrida Tenaga Surya dan Bayu terlebih dahulu, kemudian dilanjutkan dengan pembangunan prototype sesuai dengan rancangan yang sudah dibuat sebelumnya.

3. Pengujian Alat

Peneliti melakukan pengujian alat untuk mengamati dan mengetahui bagaimana hasil kinerja dari alat yang telah dibuat.

\section{Observasi}

Peneliti melakukan pencatatan dan pengumpulan data secara tepat dan benar dari hasil pengamatan alat yang telah diuji dan dijadikan kajian untuk analisa penelitian. 
5. Analisa Alat

Peneliti melakukan analisa dari hasil kajian observasi dimana telah didapatkan data dari hasil pengujian alat, pada tahap ini juga dilakukan evaluasi kesalahan kesalahan apa saja yang terjadi pada hasil uji alat.

6. Penulisan Laporan

Peneliti melakukan penulisan laporan dari hasil analisa pengujian alat.

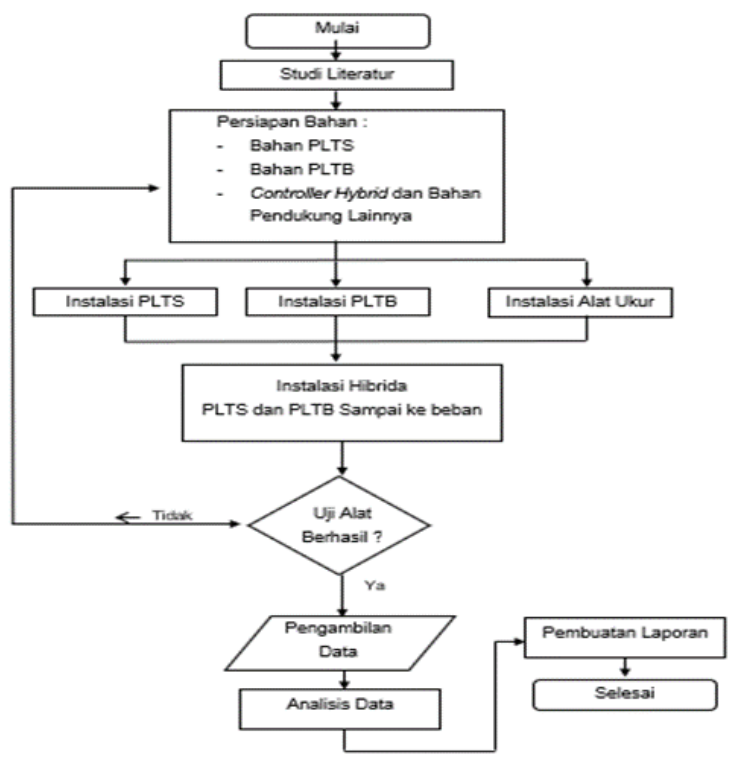

Gambar 2. Flow Chart Penelitian

\subsection{Lokasi dan Waktu Pengujian}

Penelitian Pembangkit Listrik Tenaga Hibrida Tenaga Surya dan Bayu dilakukan pada bulan Maret sampai bulan Juli tahun 2021 di Jl. Kebraon Indah Permai D19, Kel. Kebraon, Kec. Karang pilang, Kota Surabaya, Prov. Jawa Timur, Indonesia, 60222.

\section{HASIL DAN PEMBAHASAN}

\subsection{Pengujian PLTB}
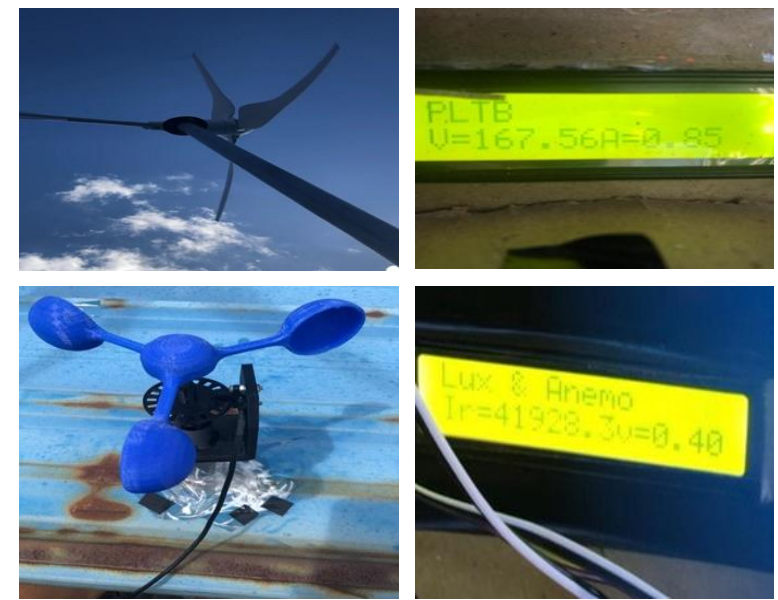

Gambar 3. Monitoring Arus, Tegangan dan Kecepatan Angin PLTB 
Pengujian dilakukan dengan melakukan pengukuran pada keluaran Pembangkit Listrik Tenaga Bayu (PLTB) yang menggunakan energi angin untuk menghasilkan suatu energi listrik dengan cara memanfaatkan bilah atau kincir angin dimana kincir angin tersebut akan disambungkan dengan generator dan dari generator inilah nanti yang akan mengubah energi kinetik menjadi energi listrik. Berikut adalah grafik dari data hasil pengujian tegangan, arus dan kecepatan angin yang telah disimpan oleh data logger selama 7 hari.

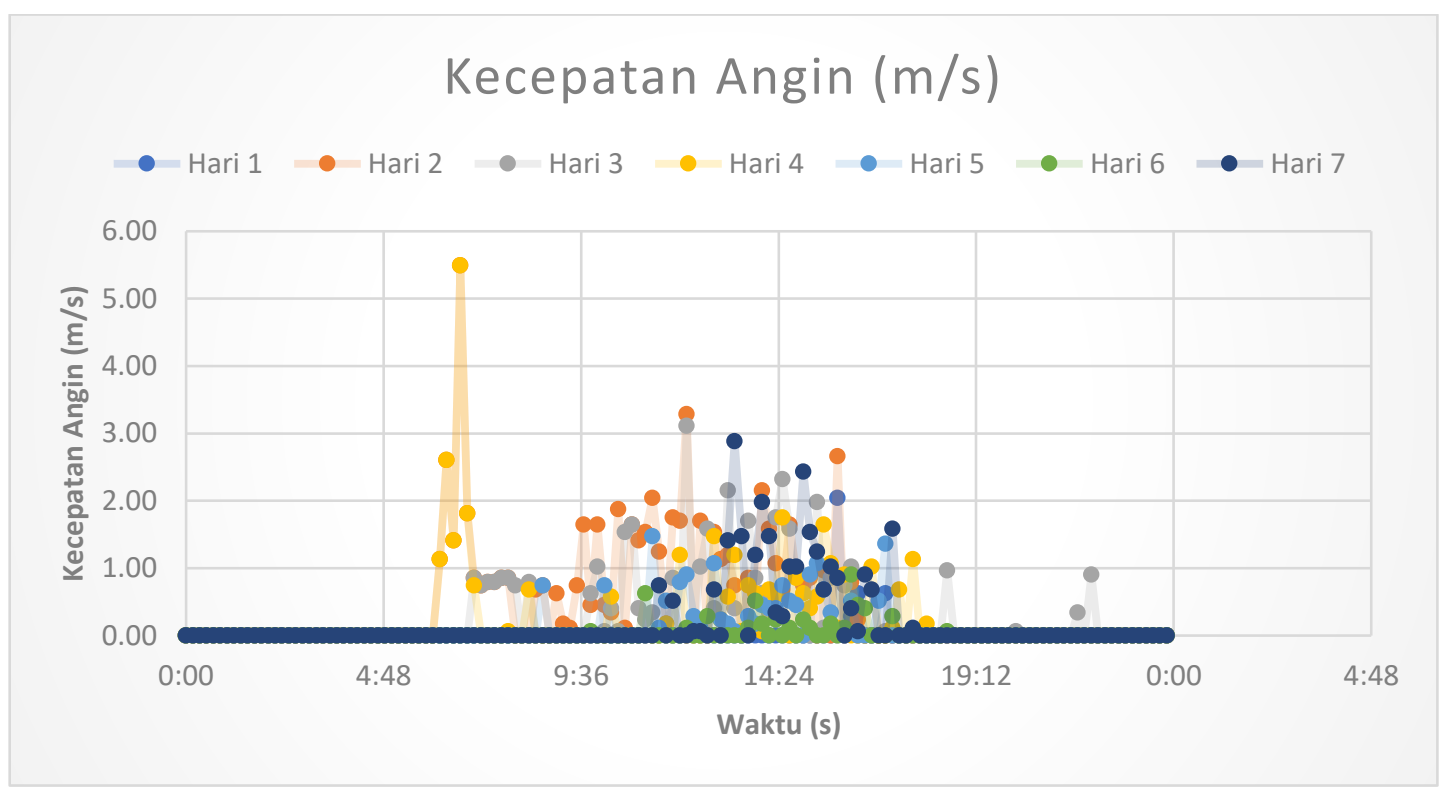

Gambar 4. Grafik Kecepatan Angin (m/s)

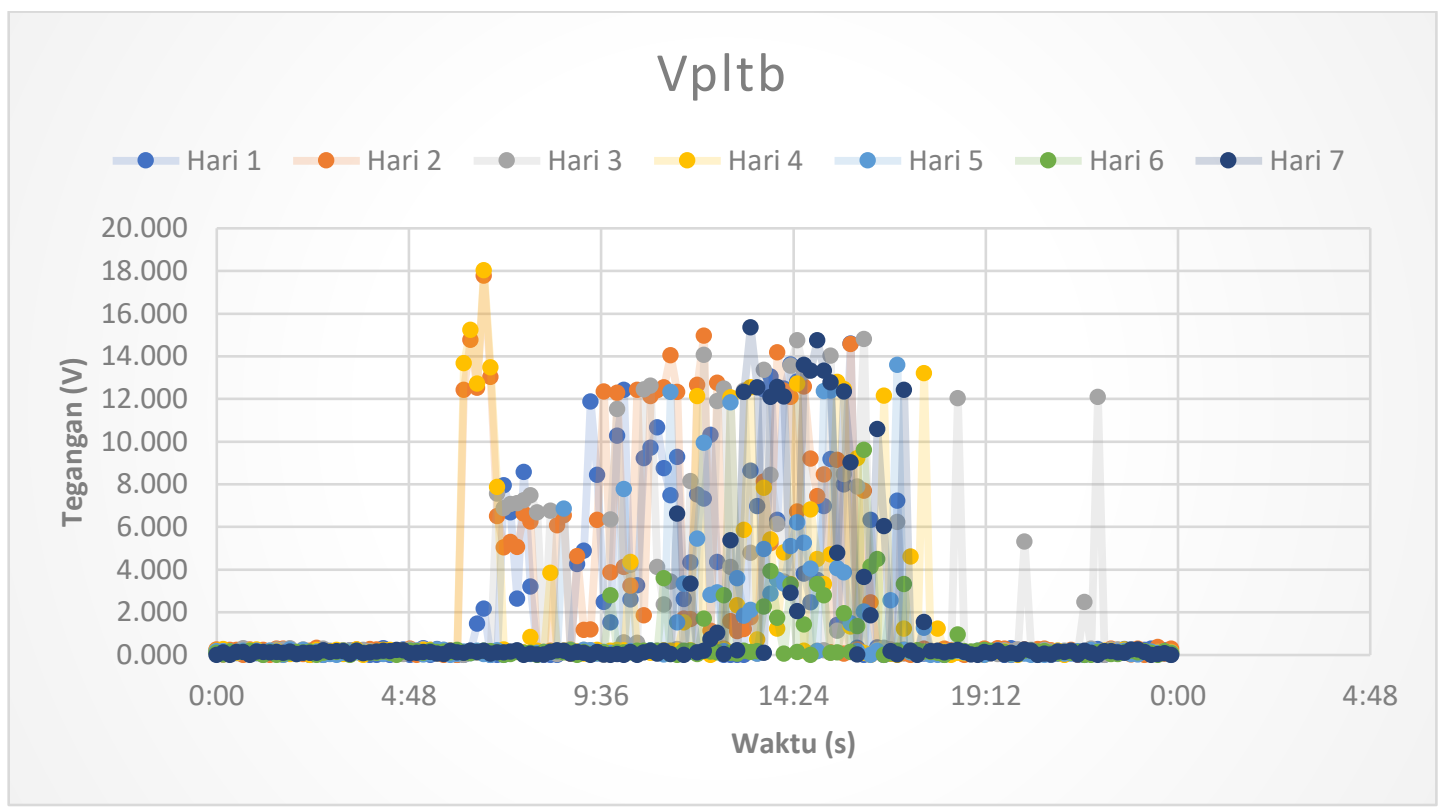

Gambar 5. Grafik Tegangan Keluaran PLTB (V) 


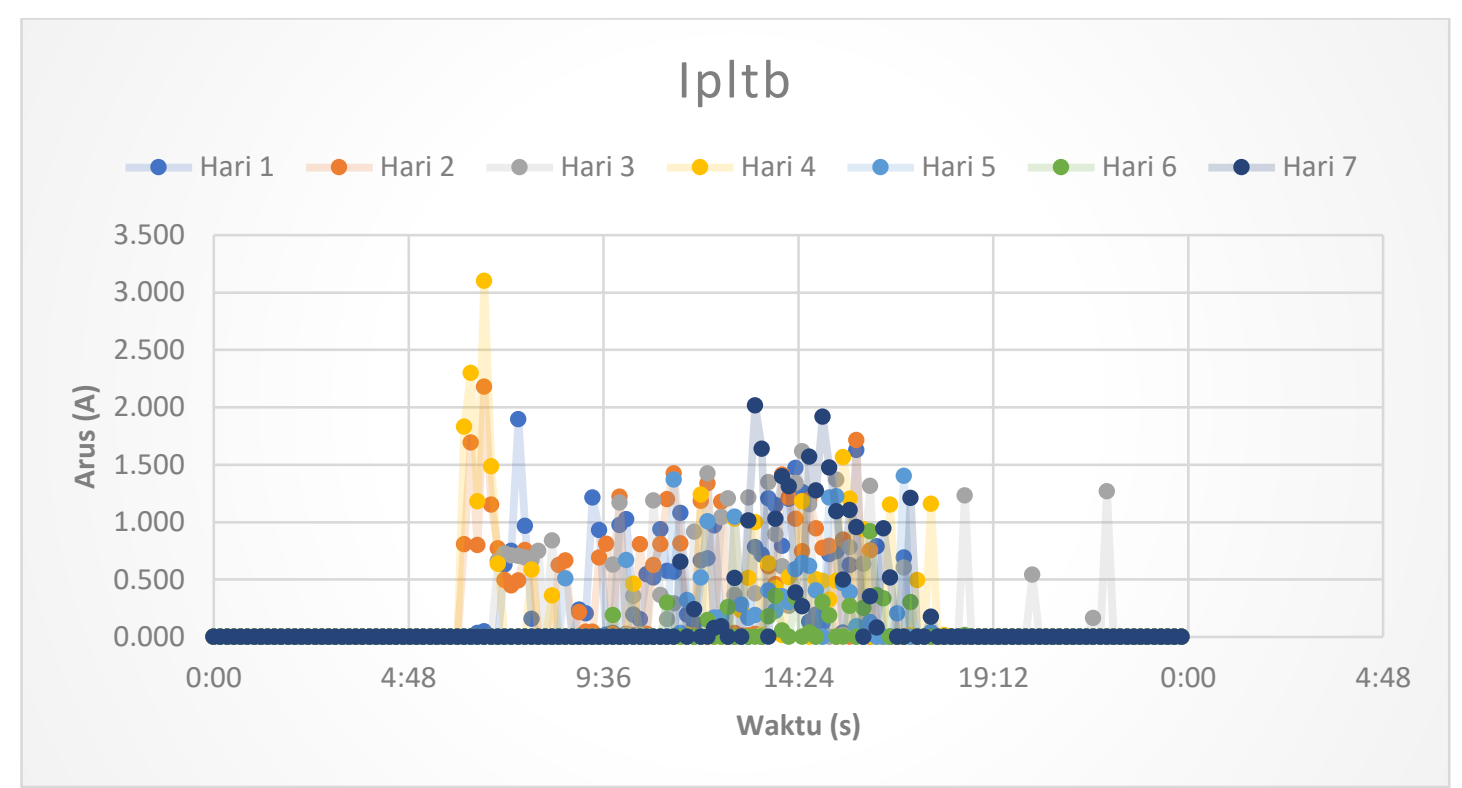

Gambar 6. Grafik Arus Keluaran PLTB (V)

Dari Grafik Kecepatan Angin (4) dapat diamati bahwa nilai kecepatan angin mempunyai grafik yang tidak stabil atau naik turun, hal ini dapat disebabkan karena faktor lokasi pengujian yang berada di daerah perkotaan dimana masih banyak terdapat gedung - gedung tinggi yang membuat hembusan angin terhalang untuk ke seluruh daerah sehingga sangat minim terjadinya angin dengan kecepatan tinggi dan stabil pada lokasi pengujian alat. Nilai Paling tinggi dari kecepatan angin yang didapat oleh Anemometer adalah sebesar $5,59 \mathrm{~m} / \mathrm{s}$ atau setara dengan $20 \mathrm{~km} /$ jam. meskipun letak PLTB berada pada ketinggian \pm 7 meter diatas permukaan tanah, namun nilai rata - rata angin yang didapatkan dalam 7 hari pengambilan data mulai pukul 05.10 sampai 17.50 adalah sebesar $0,34 \mathrm{~m} / \mathrm{s}$, angka ini termasuk dalam nilai intensitas angin yang cukup rendah. Anemometer yang terpasang sebagai sensor kecepatan angin pada kali ini juga mempunyai kekurangan yaitu pada PLTB nya yang menggunakan bilah dengan tipe sumbu horizontal sedangkan pada alat ukur nya menggunakan bilah tipe sumbu vertikal. [5]

Kemudian pada Grafik Tegangan PLTB (5), dapat diamati bahwa nilai tegangan juga bersifat fluktuatif atau tidak stabil, hal - hal yang dapat mempengaruhi nilai pengukuran tegangan yaitu pada proses penaikan tegangan dari $12 \mathrm{~V}$ ke $220 \mathrm{~V}$ yang menggunakan trafo dimana trafo sendiri mempunyai nilai tahanan murni. Presisi atau nilai ketepatan alat ukur juga perlu diperhatikan dalam pengukuran tegangan ini, dimana ZMPT101B sendiri adalah alat ukur yang lebih presisi ketika digunakan untuk mengukur tegangan $220 \mathrm{~V}$ atau standar PLN, sehingga ketika diberikan tegangan dengan nilai yang kecil maka akan memberikan nilai eror yang relatif cukup besar. Dapat diamati dari grafik dimana hampir semua data tegangan tidak dapat mencapai nilai presisi pas sebesar $0,00 \mathrm{~V}$ secara konstan. Nilai tegangan rata - rata dalam 7 hari pada mulai pukul 05.10 hingga pukul 17.50 hanyalah didapatkan nilai sebesar $3,35 \mathrm{~V}$, nilai ini sangatlah minim untuk PLTB melakukan pengisian terhadap dimana baterai sendiri membutuhkan nilai tegangan sebesar $12 \mathrm{~V}$, sedangkan nilai tegangan tertinggi yang didapat pada data rekaman adalah sebesar 330,36 $\mathrm{V}$ atau setara dengan tegangan sebesar $18 \mathrm{~V}$ dimana berada pada kecepatan angin maksimal yaitu sebesar $5,49 \mathrm{~m} / \mathrm{s}$ pada hari kamis pukul 06.40 . 
Lalu pada Grafik Arus PLTB (6), hasil yang didapat juga tidak jauh berbeda dengan grafik tegangan dan kecepatan anginnya. Dapat diamati bahwa nilai arus juga bersifat fluktuatif atau tidak stabil, Nilai rata -rata yang didapatkan dari hasil pengujian dan perekaman arus PLTB selama 7 hari pada pukul 05.10 hingga pukul 17.50 adalah sebesar 0,31 A untuk tiap fasanya, sedangkan untuk nilai arus tertinggi nya yang didapatkan sebesar 3,09 A. karena PLTB menggunakan generator sinkron 3 fasa, maka harusnya PLTB mempunyai nilai arus dan tegangan yang sama atau tidak jauh pada tiap fasanya. hal - hal yang dapat mempengaruhi dari nilai pengukuran arus salah satunya juga nilai resistif yaitu seperti penjelasan pada grafik tegangan yaitu jenis tipe pemilihan kabel, kekencangan baut dan kebersihan pada terminal dimana pengaruhnya disini adalah dengan Losses atau peristiwa hilangnya daya. [6]

\subsection{Pengujian PLTS}

Pada pengukuran Pembangkit Listrik Tenaga Surya (PLTS) yang menggunakan energi surya untuk menghasilkan energi listrik dengan cara memanfaatkan sel surya pada modul surya dimana irradiance matahari akan diserap dan akan diubah dari energi foton menjadi energi listrik. Berikut adalah grafik dari data hasil pengujian tegangan, arus dan intensitas cahaya matahari yang telah disimpan oleh data logger selama 7 hari.
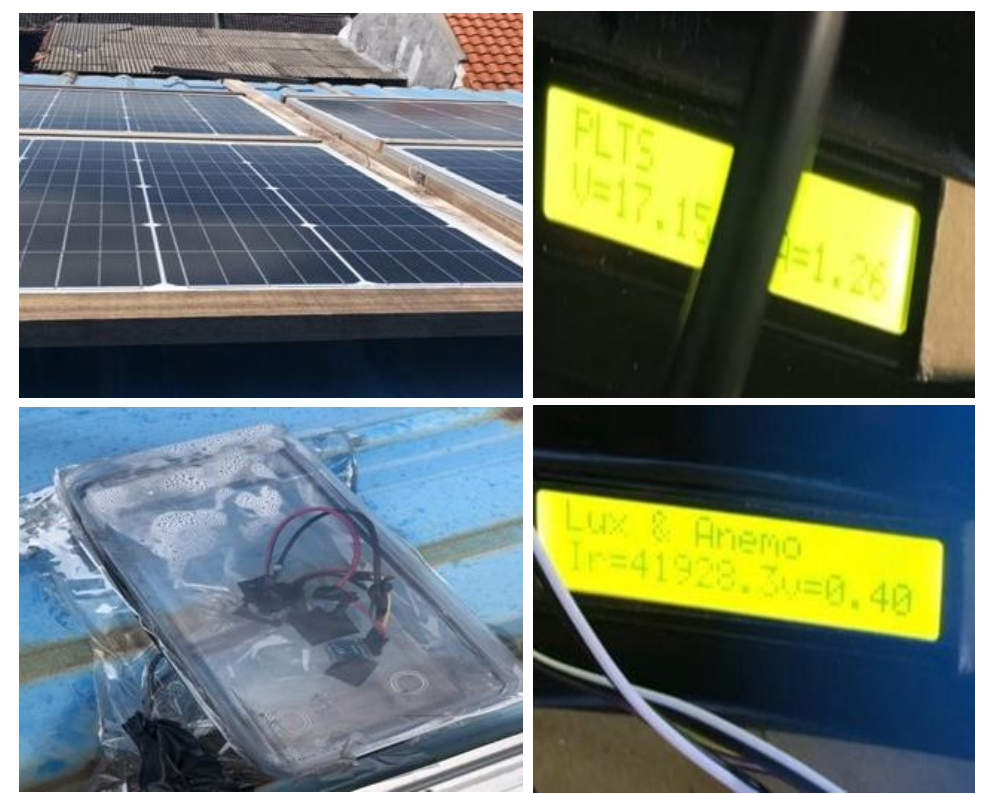

Gambar 7. Monitoring Arus, Tegangan dan Intensitas Cahaya PLTS 
Vol. 11, No. 1, Juni 2021, P-ISSN 2356-1505, E-ISSN 2656-9175

https://doi.org/10.33322/sutet.v11i1.1455

\section{LUX}

$\bullet$ Hari $1 \bullet$ Hari $2 \bullet$ Hari $3-$ Hari $4 \bullet-$ Hari $5 \bullet$ Hari $6 \bullet$ Hari 7

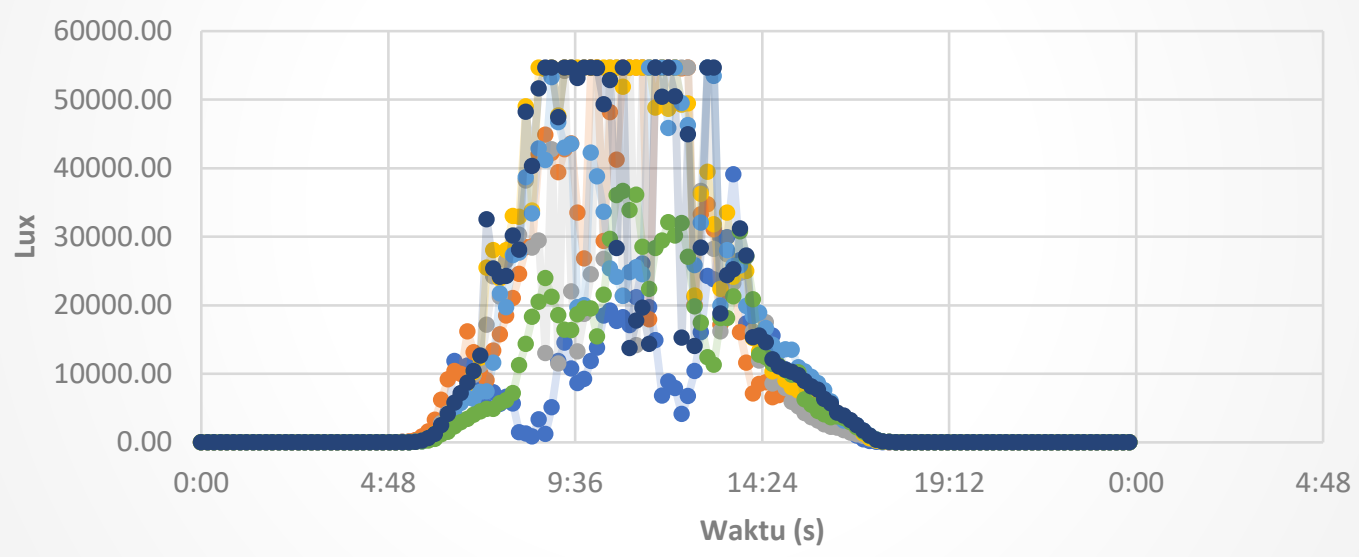

Gambar 8. Grafik Intensitas Cahaya Matahari (lux)

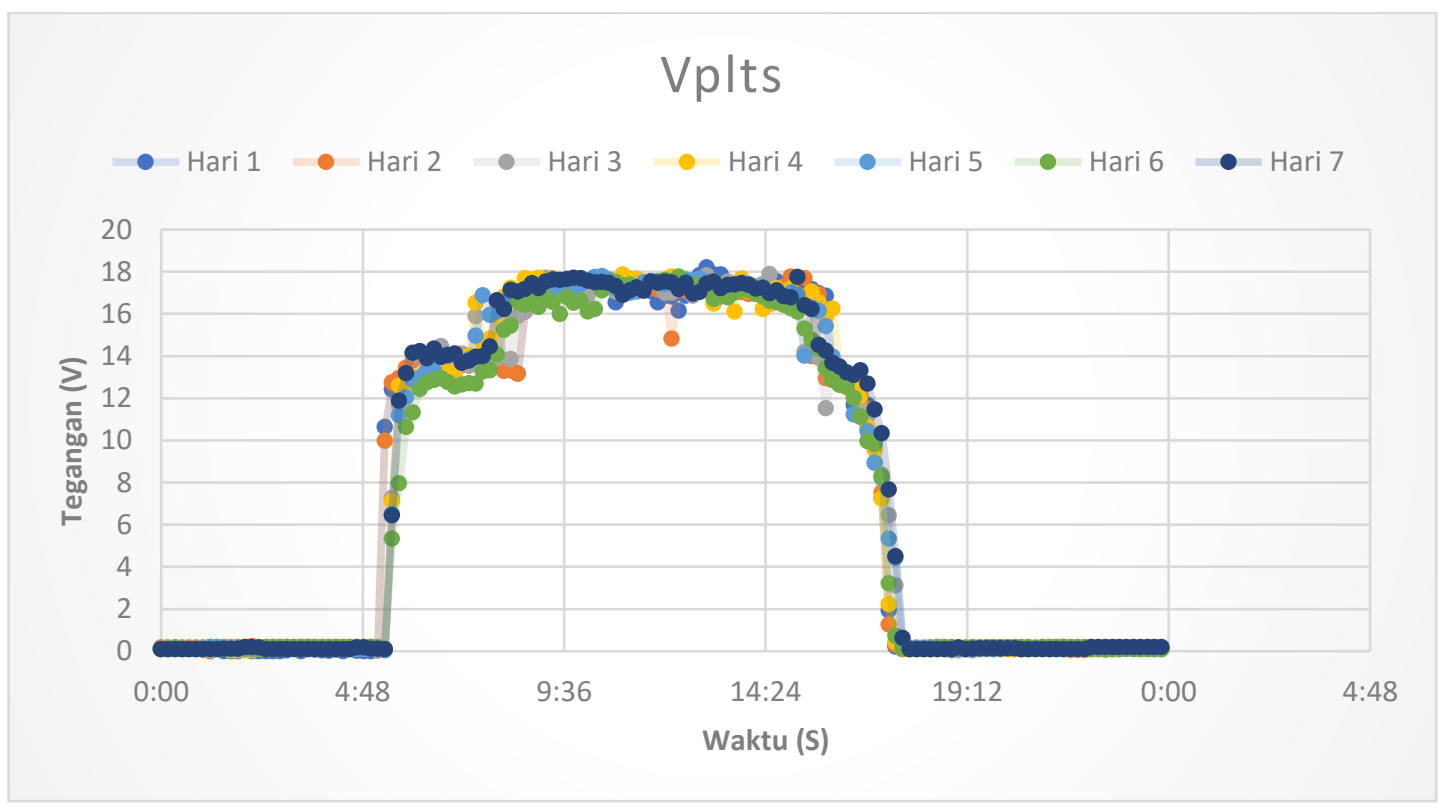

Gambar 9. Grafik Tegangan Keluaran PLTS (V) 


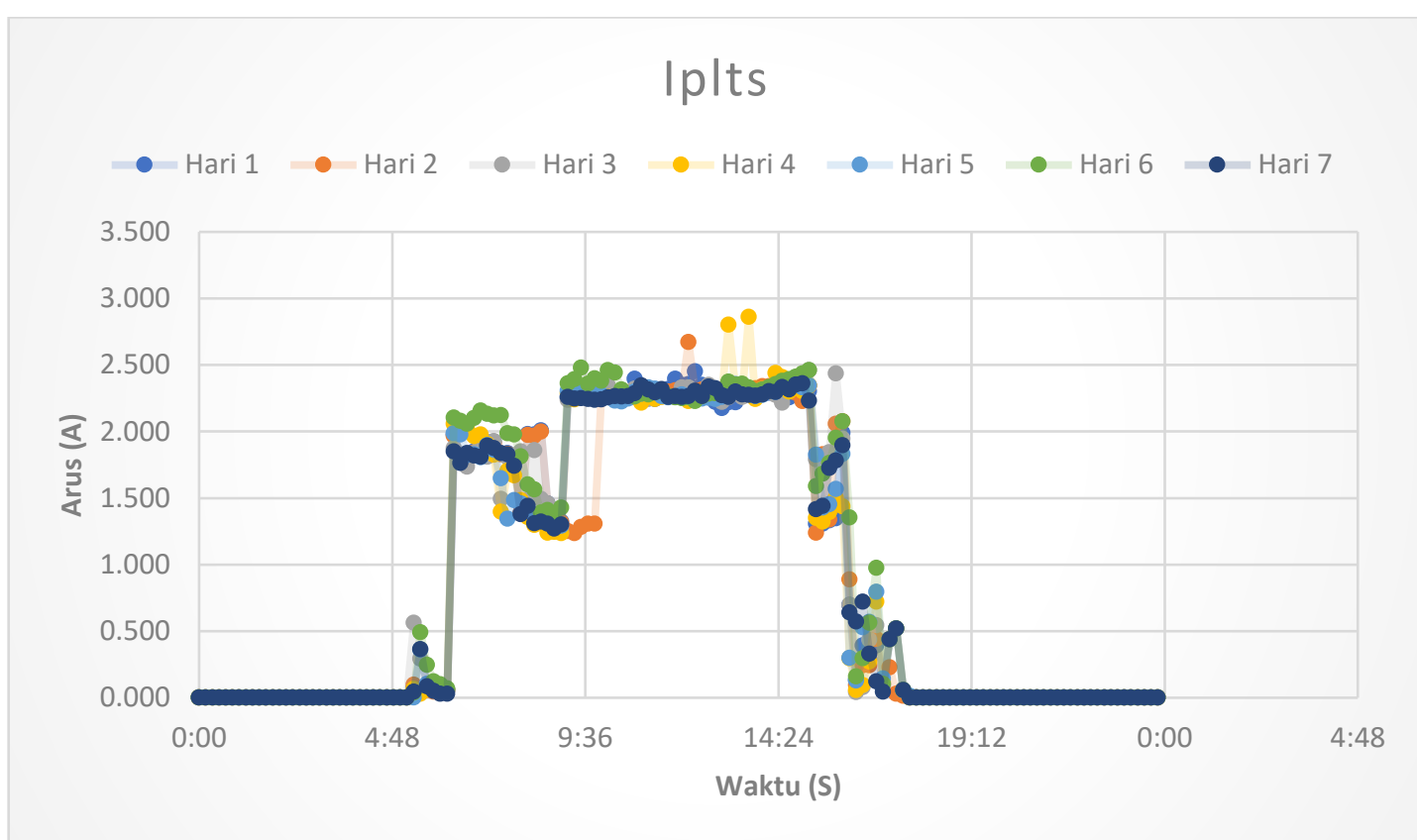

Gambar 10. Grafik Arus Keluaran PLTS (V)

Dari Grafik Lux Matahari (8) dapat diamati bahwa nilai lux mempunyai grafik yang cukup fluktuatif juga, hal ini dapat disebabkan karena faktor cuaca atau iklim yang berubah - ubah. dilakukan pengukuran lux adalah dengan tujuan untuk melihat terang atau mendungnya matahari pada jam tersebut. Nilai rata - rata yang didapatkan selama 7 hari pengambilan data adalah sebesar 19624,68 lux pada jam operasi kerja mulai pukul 05.10 pagi hingga pukul 17.50 sore, sedangkan untuk nilai terbesar dari lux pada jam operasi kerja adalah sebesar 54612,5.

Kemudian pada Grafik Tegangan PLTS (9), dapat diamati bahwa nilai tegangan pada PLTS cukup mengalami kestabilan diantara range tegangan 16 hingga $18 \mathrm{v}$ mulai pukul 09.00 pagi hingga 15.00 sore. Nilai tegangan Rata - Rata dari 7 hari pengambilan data dari mulai pukul 05.10 pagi hingga 17.50 Sore adalah sebesar $14,50 \mathrm{~V}$ dengan nilai tertingginya sebesar 18,2 V. Faktor yang dapat mempengaruhi perbedaan grafik dengan lux salah satunya adalah bahwa nilai tegangan mempunyai range yang cukup kecil jika dibandingkan dengan range nilai luxnya, pada kondisi nilai lux diatas 12.000 tegangan sudah dapat mencapai nilai \pm 17 . Kemudian faktor selanjutnya juga dapat disebabkan karena sedikit perbedaan irradiance matahari terhadap lux, hal ini dapat diamati pada data yaitu ketika pagi hari dan sore hari dengan nilai lux yang sama. nilai tegangan yang didapat pada sore hari dapat lebih tinggi dibandingkan nilai tegangan pada pagi hari, hal ini dikarenakan tingkat Irradiance pada sore hari jauh lebih besar dibandingkan ketika pagi hari ketika matahari baru saja muncul. Lalu faktor pemasangan kabel yang menggunakan terminal seperti baut juga harus dipastikan kekencangannya serta kebersihan dari baut dan lapisan luar panel PLTS yang harus dipastikan bersih dan tidak berdebu dimana ketiga hal tersebut dapat mempengaruhi nilai resistifnya yang juga dapat mempengaruhi nilai tegangan yang dihasilkan oleh PLTS. Lalu faktor kesalahan pengukuran juga bisa terdapat pada presisi alat ukur dimana masalah yang ada pada pengukuran tegangan DC PLTS kali ini adalah nilai tegangan yang sesuai dengan alat ukur tidak stabil atau berubah -ubah karena ada nya faktor eror pengukuran dari sensor. [7] 
Lalu pada Grafik Arus PLTS (10), dapat diamati bahwa nilai arus juga bernilai cukup stabil mengikuti grafik tegangannya, Nilai rata - rata dari hasil perekaman data selama 7 hari di jam operasi kerja mulai pukul 05.10 pagi hingga 17.50 Sore didapat sebesar 1,65 $\mathrm{A}$ dengan nilai tertinggi arusnya sebesar 2,86 A. Lalu faktor lainnya yang dapat menimbulkan Losses adalah panel yang terlalu panas karena temperatur nya yang cukup tinggi sehingga dapat menyebabkan turunnya daya yang dihasilkan oleh PLTS. Kapasitas yang terlalu besar dengan beban yang relatif kecil seperti simulasi pada penelitian kali ini juga dapat dikatakan sebagai losses dimana arus yang dibutuhkan sangatlah kecil, sehingga arus yang dihasilkan dari total 4 panel yang dipasang secara paralel dimana memungkinkan untuk mencapai nilai arus hingga sebesar $22 \mathrm{~A}$, hanya teraliri paling maksimum $\pm 2 \mathrm{~A}$ menuju beban.

\subsection{Menentukan Energi Listrik Yang Dihasilkan}

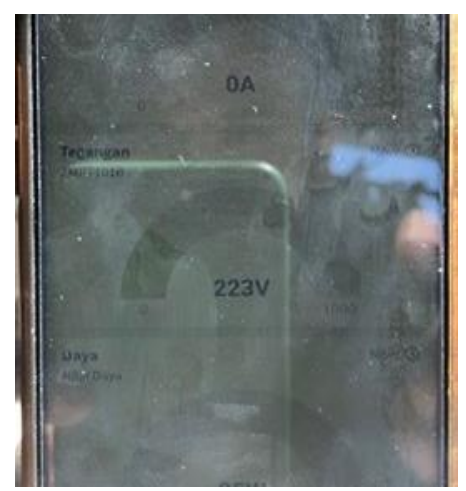

Gambar 11. Proses Monitoring Tegangan dan Arus Ke Beban

Tabel 1. Nilai Rata Rata Hasil Pengujian PLTB

\begin{tabular}{|c|c|c|c|c|c|}
\hline No & Jam & $\begin{array}{c}\text { Kec. } \\
\text { Angin } \\
(\mathrm{m} / \mathrm{s})\end{array}$ & $\begin{array}{c}\text { Tegangan } \\
(\mathrm{V})\end{array}$ & Arus (A) & $\begin{array}{c}\text { Daya } \\
(\mathrm{W})\end{array}$ \\
\hline 1 & 11.00 & 0,362 & 3,412 & 0,234 & 2,299 \\
\hline 2 & 11.10 & 0,476 & 3,743 & 0,329 & 3,285 \\
\hline 3 & 11.20 & 0,770 & 6,007 & 0,616 & 7,566 \\
\hline 4 & 11.30 & 0,270 & 2,855 & 0,169 & 2,008 \\
\hline 5 & 11.40 & 0,170 & 1,355 & 0,070 & 0,223 \\
\hline 6 & 11.50 & 0,520 & 2,068 & 0,185 & 1,491 \\
\hline 7 & 12.00 & 0,736 & 6,072 & 0,588 & 6,561 \\
\hline
\end{tabular}


Tabel 2. Nilai Rata Rata Hasil Pengujian PLTS

\begin{tabular}{|c|c|c|c|c|c|}
\hline No & Jam & $\begin{array}{c}\text { Intensitas } \\
\text { Cahaya } \\
(\text { lux })\end{array}$ & $\begin{array}{c}\text { Tegangan } \\
(\mathrm{V})\end{array}$ & Arus (A) & $\begin{array}{c}\text { Daya } \\
(\mathrm{W})\end{array}$ \\
\hline 1 & 11.00 & 44491,500 & 17,434 & 2,271 & 39,590 \\
\hline 2 & 11.10 & 36996,832 & 17,340 & 2,284 & 39,592 \\
\hline 3 & 11.20 & 43364,500 & 17,354 & 2,282 & 39,588 \\
\hline 4 & 11.30 & 40818,166 & 17,404 & 2,275 & 39,591 \\
\hline 5 & 11.40 & 48184,498 & 17,456 & 2,268 & 39,588 \\
\hline 6 & 11.50 & 49567,334 & 17,452 & 2,269 & 39,592 \\
\hline 7 & 12.00 & 47143,000 & 17,336 & 2,284 & 39,596 \\
\hline
\end{tabular}

Tabel 3. Nilai Rata Rata Hasil Pengujian Output Sistem Ke Beban

\begin{tabular}{|c|c|c|c|c|}
\hline No & Jam & $\begin{array}{c}\text { Tegangan } \\
(\mathrm{V})\end{array}$ & Arus $(\mathrm{A})$ & $\begin{array}{c}\text { Daya } \\
(\mathrm{W})\end{array}$ \\
\hline 1 & 11.00 & 182,8 & 0,084 & 14,908 \\
\hline 2 & 11.10 & 227,6 & 0,08 & 18,258 \\
\hline 3 & 11.20 & 217,2 & 0,068 & 14,714 \\
\hline 4 & 11.30 & 204,6 & 0,068 & 12,662 \\
\hline 5 & 11.40 & 218,6 & 0,07 & 15,302 \\
\hline 6 & 11.50 & 223 & 0,064 & 14,238 \\
\hline 7 & 12.00 & 229,6 & 0,064 & 14,64 \\
\hline
\end{tabular}

Dari Ketiga Tabel diatas, dapat dilihat bahwa beban telah berhasil disimulasikan dengan menggunakan hasil inputan daya dari PLTB dan PLTS dimana hasil dari daya didapatkan dari hasil perkalian arus dengan tegangannya., terdapat kekurangan dari sistem monitoring IoT yang dimana membutuhkan wifi untuk mengirim data dimana terdapat sambungan wifi yang terputus - putus dikarenakan letak wifi yang berada di lantai yang berbeda. [8]

Data yang diambil untuk perhitungan dibawah ini adalah data dari salah satu hari yang telah terekam di data logger pada hari selasa tanggal 29 juni 2021 dari pukul 00.00 hingga 23.50 WIB, Dimana didapatkan nilai rata - rata pemakaian daya selama beban bekerja yaitu sebesar 17,06 W pada pukul 05.10 hingga 19.30 atau setara 14,2 jam. Sedangkan pada data PLTB selama 24 jam didapatkan nilai rata - rata daya masuk sebesar 6,71 W selama 10,1 jam. Selanjutnya pada tabel data PLTS selama 24 jam (4.5), didapatkan nilai rata - rata daya masuk selama 12,3 jam adalah sebesar 25,67 W. didapatkan nilai energi keluar dan masuk dalam satu hari melalui rumus mencari nilai energi sesuai dengan persamaan Rumus Energi sebagai berikut :

$$
\mathrm{W}=\mathrm{P} \times \mathrm{t}
$$

Total Energi yang masuk kira -kira dalam 24 jam adalah sebesar:

$\mathrm{Wpltb}=$ Ppltb $\times \mathrm{t}=6,71 \mathrm{~W} \times 10,1$ jam $=67,77 \mathrm{Wh}$

Wplts $=$ Pplts $\times t=25,76 \mathrm{~W} \times 12,3$ jam $=316,84 \mathrm{Wh}$ 
Total Wmasuk $=384,61 \mathrm{Wh}$

Total Energi Beban yang digunakan kira -kira dalam 14,2 jam adalah sebesar:

Total Wterpakai $=$ Pbeban $\times \mathrm{t}=17,06 \mathrm{~W} \times 14$ jam $=242,25 \mathrm{Wh}$

Total Energi Sisa:

Total Wmasuk - Wterpakai $=384,61-242,25 \mathrm{Wh}=142,36 \mathrm{Wh}$

Dari hasil perhitungan diatas, dapat disimpulkan bahwa Energi yang masuk mampu untuk mensuplai kebutuhan beban berjenis pompa aerator $25 \mathrm{~W}$ hingga 14,2 jam dengan menyisakan energi sebesar 142,36 Wh yang dapat disimpan didalam baterai.[9]

\subsection{Optimalisasi Sistem}

Setelah melakukan pengujian dan pengolahan data, maka berikut dipaparkan faktorfaktor apa saja yang dapat memperbaiki atau mengoptimalisasi sistem pembangkit listrik hibrida tenaga surya dan bayu agar hasil yang didapatkan dapat lebih baik:

\section{Penaik Tegangan PLTB}

Karena nilai angin yang cukup kecil sehingga mengakibatkan tegangan PLTB dibawah $12 \mathrm{~V}$ Sehingga tidak dilakukan nya pengecasan ke baterai, oleh karena itu perlu diberikan sebuah alat penaikan tegangan dari $2 \mathrm{~V}$ ke $12 \mathrm{~V}$ agar dengan nilai intensitas angin yang kecil dan putaran yang minim, sudah dapat mengisi daya baterai.

\section{Baterai}

Karena faktor baterai yang digunakan kali ini adalah 2 buah baterai bekas yang digunakan untuk backup supply daya di Gardu Induk (GI), sehingga nilai kualitas baterai yang ada sudah menurun untuk melakukan charging dan discharging. maka yang harus dilakukan adalah mengganti baterai yang sudah bekas dengan baterai baru yang mempunyai kapasitas sesuai dengan beban yang dibutuhkan dan tentunya juga tetap menggunakan baterai pada dengan posisi pemakaian 50 $\%$ dari kapasitas baterai agar umur dari baterai ini cukup lama untuk tetap dapat digunakan.

\section{Penstabil tegangan $220 \mathrm{~V}$}

Karena didapatkan nilai tegangan yang berlebih pada output dari inverter, maka tentu diperlukan alat penstabil tegangan $220 \mathrm{~V}$ agar nilai tegangan yang berlebih tersebut selalu dikonversikan ke $220 \mathrm{~V}$ sehingga tidak merusak peralatan ketika disambungkan dengan beban rumah yang memerlukan standar PLN yaitu dengan frekuensi $50 \mathrm{~Hz}$ dan tegangan sebesar 220 V.[10]

4. Penambahan Beban

Karena didapatkan nilai daya keluaran dari hasil penjumlahan antara daya PLTS dan daya PLTB lebih besar dibandingkan dengan nilai daya yang sangat kecil untuk digunakan oleh beban, maka tentu diperlukannya penambahan beban lagi agar daya yang berlebih tersebut tidak menjadi faktor losses. 


\section{KESIMPULAN DAN SARAN}

\subsection{Kesimpulan}

1) Pada penelitian kali ini, penulis telah berhasil untuk melakukan perancangan dan pembangunan gabungan antara dua pembangkit listrik yaitu PLTS dan PLTB menggunakan controller ber tipe hybrid. Setelah melalui controller, Output tegangan DC $12 \mathrm{~V}$ akan disambungkan ke baterai $12 \mathrm{~V}$, kemudian setelah dari baterai output akan disalurkan ke beban melalui inverter yaitu dari $12 \mathrm{~V}$ ke $220 \mathrm{~V}$.

2) sistem hibrida dipasangkan alat monitoring yang berbasis data logger untuk monitoring tegangan dan arus input dari PLTB dan PLTS secara online. sedangkan basis loT untuk monitoring tegangan dan arus output keluaran dari inverter ke beban secara online.

3) Sistem Pembangkit Listrik Hibrida Tenaga Surya dan Bayu telah berhasil untuk dapat mensuplai daya hingga ke pompa aerator kolam 25 W. Namun sempat ditemukan masalah dimana nilai tegangan yang dihasilkan oleh inverter sangatlah tinggi yaitu melebihi $250 \mathrm{~V}$. Sehingga untuk sistem yang lebih baik perlunya dilakukan penambahan beban serta penstabil tegangan $220 \mathrm{~V}$ pada hasil keluaran inverter.

\subsection{Saran}

1) Sebaiknya untuk membuat sebuah sistem dengan hasil yang lebih baik, harus dipastikan bahwa alat - alat atau komponen yang dipakai adalah baru atau belum pernah dipakai sebelumnya.

2) Agar PLTB dapat bekerja secara maksimal, sebaiknya PLTB dipasang pada lokasi yang mudah untuk terkena angin seperti daerah pantai ataupun pegunungan.

\section{UCAPAN TERIMAKASIH}

Dengan ini penulis mengucapkan terima kasih yang sebesar-besarnya kepada seluruh dosen, staf dan instruktur dalam lingkup S1 Teknik Elektro Institut Teknologi PLN serta kedua orang tua, rekan dan kerabat yang telah memberikan dukungan.

\section{DAFTAR PUSTAKA}

[1] D. I. P. Wangi-wangi, S. W. Widyanto, S. Wisnugroho, and M. Agus, "SURYA PADA PEMBANGKIT LISTRIK TENAGA HIBRID," pp. 1-12, 2018.

[2] Kementrian Energi dan Sumber Daya Mineral, "RENCANA USAHA PENYEDIAAN TENAGA LISTRIK PT. PLN (persero) 2018-2027," p. 233.

[3] K. ESDM and D. Ketenagalistrikan, "Statistik Ketenaga Listrikan Tahun 2018," J. Chem. Inf. Model., vol. 53, no. 9, pp. 92-93, 2019.

[4] Dimas Hardiantoro \& Frederik Haryanto Sumbung, "RANCANG BANGUN UNIT PEMBANGKITAN DAN MODUL PENGUKURANNYA UNTUK PEMBANGKIT LISTRIK TENAGA HYBRID (ANGIN DAN MATAHARI),” pp. 1-15, 2016.

[5] M. Nuarsa, J. Teknik, M. Fakultas, and T. Universitas, "TERHADAP UNJUK KERJA TURBIN ANGIN POROS HORIZONTAL,” vol. 3, no. 1, pp. 50-59, 2013.

[6] M. N. Habibie, A. Sasmito, and R. Kurniawan, "Kajian Potensi Energi Angin Di Wilayah Sulawesi Dan Maluku," J. Meteorol. dan Geofis., vol. 12, no. 2, p. 3, 2011. 
[7] S. Yuliananda, G. Sarya, and R. Retno Hastijanti, "Pengaruh Perubahan Intensitas Matahari Terhadap Daya Keluaran Panel Surya," J. Pengabdi. LPPM Untag Surabaya Nop., vol. 01, no. 02, p. 2, 2015.

[8] M. Ir. I Nyoman Budiastra, MKes., M. E. M. Ir. Cokorde Gede Indra Partha, and M. Ir. I Wayan Arta Wijaya, M.Erg., "HIBAH PENELITIAN DATA LOGGING SUHU , ARUS DAN TEGANGAN BERBASIS MIKROKONTROLER ARDUINO UNO R3 PROGRAM STUDI TEKNIK ELEKTRO UNIVERSITAS UDAYANA OKTOBER 2015," 2015.

[9] A. Wahid, Ms. Ir. Junaidi, and M. Dr. Ir. H. M. Iqbal Arsyad, "Analisis Kapasitas Dan Kebutuhan Daya Listrik Untuk Menghemat Penggunaan Energi Listrik Di Fakultas Teknik Universitas Tanjungpura," J. Tek. Elektro UNTAN, vol. 2, no. 1, p. 10, 2014.

[10] I. Darmaputra Catra Daksa, Achmad Imam Agung, Subuh Isnur Haryudo, "PROTOTIPE PENSTABIL TEGANGAN PADA PEMBANGKIT LISTRIK TENAGA MIKRO HIDRO," 2018. 